\title{
Bilier stent ilişkili duedonal bezoar
}

\author{
Biliary stent-associated duodenal bezoar
}

\author{
Hakan Ümit ÜNAL ${ }^{1}$, Burçak GÜMÜŞ², Tuba OLCAY³ ${ }^{3}$ Uğur YILMAZ \\ Başkent Universitesi Istanbul Hastanesi, ${ }^{1}$ Gastroenteroloji Kliniği, ${ }^{2}$ Radyoloji Kliniği, Istanbul \\ Başkent Üniversitesi Ankara Hastanesi, ${ }^{3}$ Iç Hastalıkları Kliniği, ${ }^{4}$ Gastroenteroloji Kliniği, Ankara
}

Bezoar gastrointestinal sistemde sindirilemeyen materyallerin birikmesi ile gelişir. Ust gastrointestinal sistem endoskopilerinin \% l'inden daha azında saptanan bezoar oluşumu sağllklı bireylerde daha da nadirdir. Bizim hastamız bilier stent iliskili bezoar vakasıdır.

Anahtar kelimeler: Bezoar, gastrik obstrüksiyon, bilier stent

\section{GİRIS}

Bezoar, yutulan yabancı cisimler veya gıda maddelerinin bir kitle etkisi oluşturacak şekilde gastrointestinal sistem lümeninde yoğunlaşması sonucu oluşur. Oluşan bezoarın zamanla gastrointestinal sistemde pasajı zorlaştırması veya engellemesi sonucunda bulantı, kusma, karın ağrısı ve ileus gibi obstrüksiyon bulguları ortaya çıkabilir. Bitkisel gıdaların birikmesi ile ortaya çıkan fitobezoar, özellikle kadınlarda görülen ve saç tellerinin yutulması ile ortaya çıkan trikobezoar ve bazı ilaçlara bağlı gelişen farmabezoar gibi spesifik alt gruplar yanında bu gruplara dahil edilemeyen farklı yapıda materyaller ile ortaya çıkmış bezoar tipleri tanımlanmıştır.

Bizim vakamız malign bilier darlık nedeni ile yerleştirilmiş metal bilier stent çevresinde oluşan bezoara bağlı gastrik çıkış obstrüksiyon bulguları ortaya çıkan bir olgudur.

\section{OLGU}

Kırk altı yaşında bayan sarılık ve ateş şikayetleri ile hastanemize başvurdu. Diş merkezde metastatik meme kanseri tanısı ile takip edilirken ortaya çıkan sarılığı nedeni ile yapılan tetkiklerde karaciğer hilus komşuluğunda 2,5 cm'lik metastaz ile uyumlu kitle lezyonu ve sağda belirgin olmak üzere safra yollarında dilatasyon saptanmış. Dış merkezde endoskopik retrograd kolanjiopankreatografi uygulanarak plastik stent yerleştirilmiş ancak yeterli drenaj sağlanamamış. Fizik muayenesinde vücut sıcaklığı $38,2{ }^{\circ} \mathrm{C}$ ve belirgin ikteri olan hasta malign bilier darlık ve buna bağlı kolanjit tanısı ile hastaneye yatırıldı. Biyokimyasal testlerde; total/direkt bilirubin: 21/15 mg/dl, AST: 95 U/L,ALT: 145 U/L, ALP: 823 U/L, GGT: 1279 U/L, löksit sayısı 18.400/uL idi. Safra drenajı amacı ile
Bezoars are concretions of undigested material in the gastrointestinal tract, and are found in less than $1 \%$ of patients undergoing upper gastrointestinal endoscopy. Bezoar formation is rare in healthy subjects. Most of the patients who present with bezoar-associated complications have had no gastrointestinal disease. In this report, we present a case with biliary stent-associated bezoar.

Key words: Bezoar, gastric outlet obstruction, biliary stent

perkütan transhepatik kolanjiografi sonrası internal-eksternal drenaj kateteri yerleştirildi. Kliniği ve labovatuar değerleri hızla düzelen hastada (total/direkt bilirubin: 6,7/5,4 mg/dl, AST: 93 U/L, ALT: 42 U/L, ALP: 643 U/L, GGT: 1233 U/L, löksit sayısı 9.930/uL) darlık bölgesine perkütan kapsız metal stent yerleştirildi [ $9 \mathrm{~mm}$ çapinda ve $10 \mathrm{~cm}$ uzunluğunda biliyer kendiliğinden genişleyebilir Wallstent (Boston Scientific)]. Taburcu edilen hasta yaklaşık 1,5 ay sonra yemekten sonraki yarım saat içinde yediklerini içerir tarzda kusmaları başladığı için başvurdu. Yapılan üst gastroinestinal sistem endoskopisinde biliyer stent çevresinde lümeni belirgin şekilde daraltan ve posalı gıda artıklarının oluşturduğu bezoar izlendi (Şekil-1, 2). Biyopsi forsepsi ve yıkama ile stent çevresi te-

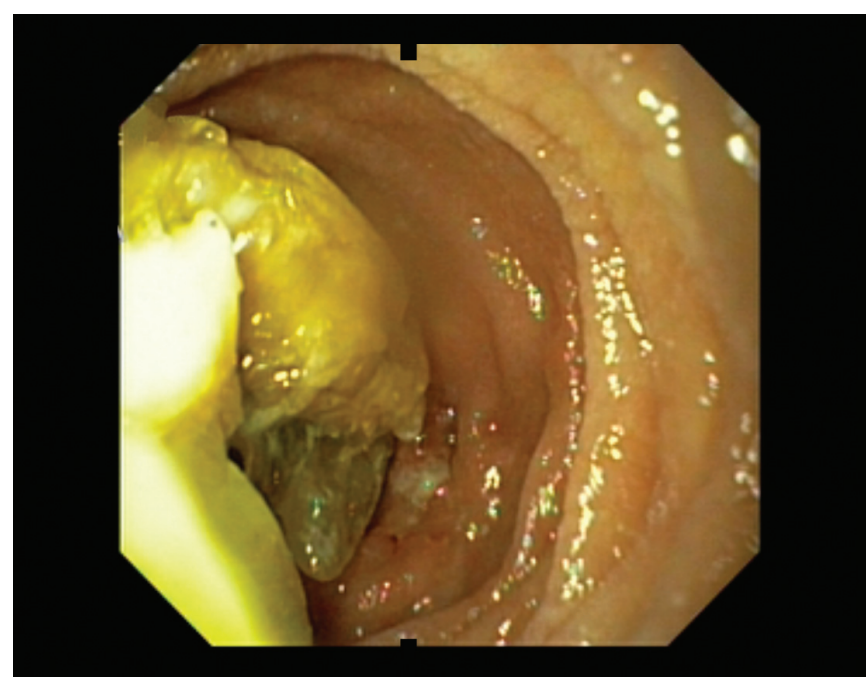

Şekil 1. Bilier stent çevresinde bezoar. 


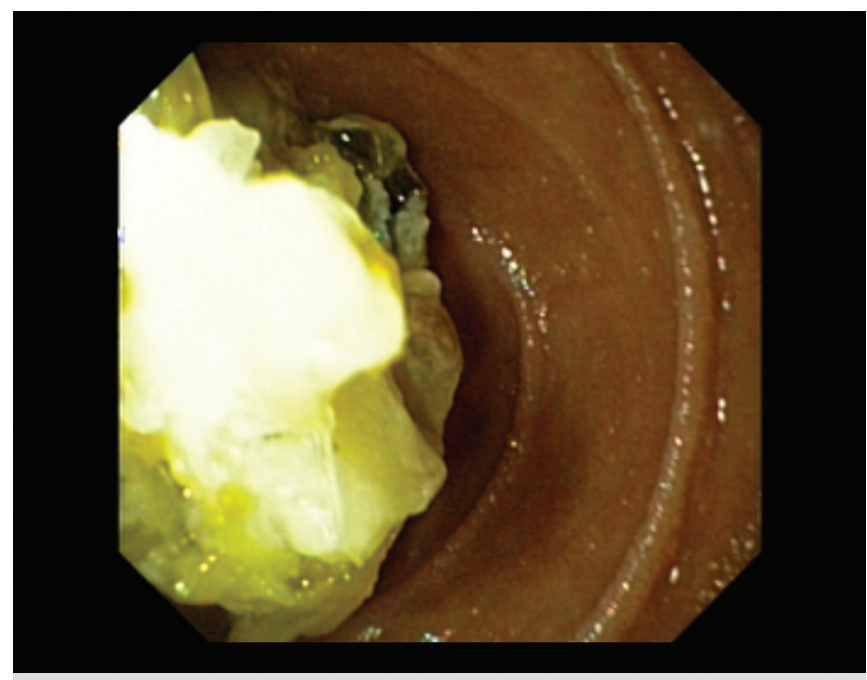

Şekil 2. Bilier stent çevresinde bezoar.

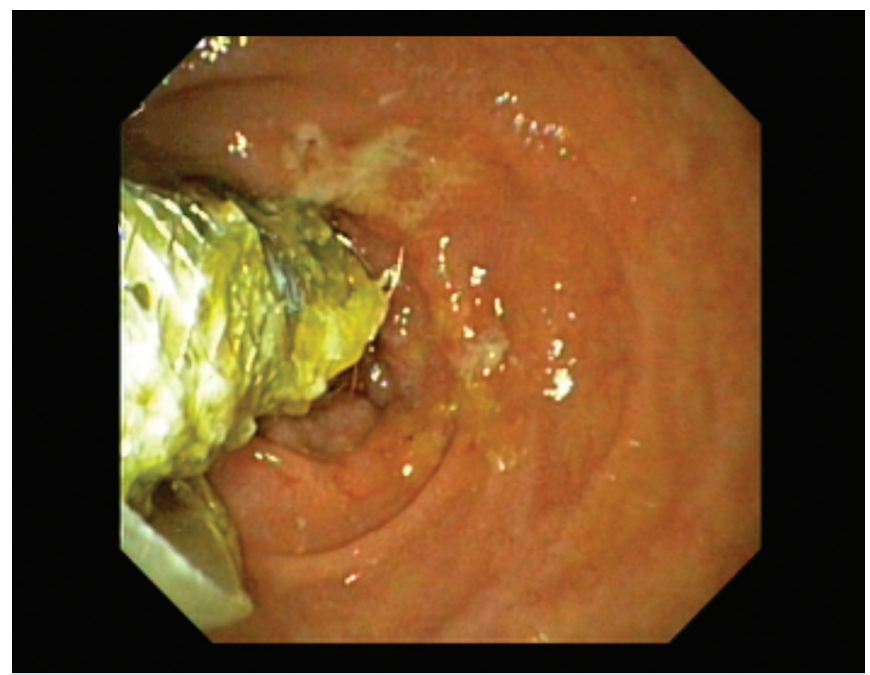

Şekil 3. Biyopsi forsepsi ile temizlendikten sonra stentin görünümü. mizlendikten sonra işleme son verildi (Şekil-3). İşlem sonrası hastanın şikayetleri tamamen düzeldi.

\section{TARTISQMA}

Malign bilier darlıklarda metal stent sık ve başarı ile uygulanan bir yöntemdir. Stentin duodenum lümenine uzanması bu bölgede pasaja direnç oluşturabilmektedir. Oluşan direnç stentin duodenum lümeninde kalan distal parçasının uzunluğu ve stent çapı ile ilişkilidir. Bizim vakamız meme kanserinin karaciğer metastazına bağlı bilier darlık ve kolanjit gelişmiş olan bir hasta idi. ERCP ile yerleştirilen plastik biliyer stent ile yeterli drenaj sağlanamamış olan hastaya perkütan biliyer drenaj uygulandı ve hastanın klinik ve labovatuarında belirgin düzelme sağlandı. Biliyer drenajın idamesi amacı ile perkütan $9 \mathrm{~mm}$ çapında $10 \mathrm{~cm}$ uzunluğunda kendiliğinden genişleyebilir Wallstent yerleştirildi. Stentin distal duodenal parçası peristaltizm yönünde uzatılarak stentin gıda artıkları ile tıkanma riski en aza indirgenmeye çalışıldı. Kolanjit tablosu kontrol altına alınan hastanın oral alımı ve iştahı düzeldi. Bunun sonucunda oral olarak alınan ve özellikle selülozdan zengin gidalar stent çevresinde birikmeye başladı ve duodenum lümeninde daralmaya neden oldu. Lüminal geçişin zamanla daralması ile önce bulantı ve hazımsızlık ardından yediklerini içerir tarzda kusmaları başladı. Stent çevresinin endoskopik olarak temizlenmesi ile hastanın bulantı ve kusmaları tamamen ortadan kalktı.
Bezoar gastrointestinal sistem fonksiyonları normal olan kişilerde nadirdir. Altta yatan gastrointestinal motilite bozuklukları veya lüminal darlıklar bezoar gelişimi açısından risk oluşturur. Yapılan çalışmalarda gastrik bezoar gelişmiş hastaların yaklaşık 2/3 ünde gastrik cerrahi veya vagotomi varlığı tespit edilmiştir (1-3). Bizim hastamızda motilite problemi olmamasına karşın duodenum lümenine uzanan metalik stentin pasaja direnç oluşturması bezoar gelişimine neden olmuştur. Endoskopik olarak stent çevresinin temizlenmesini takiben hastanın semptomları tamamen ortadan kalkmıştır. Zarling ve arkadaşlarının yaptığı çalışmada semptomlara neden olan bezoar ortadan kaldırılsa dahi hastaların yaklaşık \%20'sinde semptomların devam ettiği belirtilmektedir (4).

Malign bilier darlıklarda perkütan yol ile takılan biliyer stentler biliyer akımın idamesinin sağlanabilmesi amacı ile mümkün olduğunca geniş çaplı ve stentin distal ucunun gıda artıkları ile tıkanmasını engellemek üzere peristaltizm yönünde yerleştirilme eğilimindedir. Bu durumda duodenum 2. kitasında uzanan metal bir kafes şeklindeki stente gıdalarla alınan insoluble maddelerin takılma ve bu bölgede birikme riski artmaktadır. Kaplı stentler kullanılarak stent çevresinde bezoar oluşumunun bir ölçüde engellenebilir olabileceğini düşünmekteyiz. Ancak bu durumda hem işlem maliyeti hem de stent migrasyon ihtimali artabilir.

\section{KAYNAKLAR}

1. Robles R, Parrilla P, Escamilla C, et al. Gastrointestinal bezoars. Br J Surg 1994; 81: 1000-1.

2. Krausz MM, Moriel EZ, Ayalon A, et al. Surgical aspects of gastrointestinal persimmon phytobezoar treatment. Am J Surg 1986; 152: 52630 .

3. White NB, Gibbs KE, Goodwin A, Teixeira J. Gastric bezoar complicating laparoscopic adjustable gastric banding, and review of literature. Obes Surg 2003; 13: 948-50.

4. Zarling EJ, Thompson LE. Nonpersimmon gastric phytobezoar. A benign recurrent condition. Arch Intern Med 1984; 144: 959-61. 